\title{
The Prominent Figures and Theories in Translation
}

\author{
RoswaniSiregar \\ Al-Azhar University, Medan
}

\begin{abstract}
The topic of this paper deals with the prominent figures and some theories in translation. For those who are interested in translation in deepening the theories, its aim is twofold: (1) by knowing them there will be a clear picture about the theories of translation and the experts behind them; and (2) there will also be a comparative study about them or combining ideas in order to find that translation is an activity which requires a sophisticated knowledge of the source language and the target language. It is also generally seen as a process of communicating the foreign text by establishing the equivalence based on universal of language culture.
\end{abstract}

Keywords: prominent, figures, theories, translation, practices, source language, target language.

\section{Introduction}

Translationistransferring themessageof the source languageintothe targetlanguageby taking into accountthe meaningandconformity of stylistic. In translation process, thereare some stepsthat must be considered, i.e., preceded by lexical review and grammatical structure.

Translating can be analogized aswearingclothes, itssuitabilitydependson the wearer and perceiver. However, translation isan art, depending on whointerpret it.

Personally, the theoretical basisandapproachfor translation suggested by theorists absolutely necessary. It closely related tothe exchange of ideasandexperience,as well asscholarlyfactorandacceptance oftranslation product. Despitemanypractitionersproposedthat the experiences andhabitual is a vigorous factorin translation process, the uniformity ofthe systemand highaccuracymust be center forattention. For decades, the practice of translation groundedon varioustheoriesandapproaches, initiatedby some theorists on this field. Asit was associatedwiththe advancement of technology, thisactivitiesrelated to machineandsoftwareassisted in translation process(Jean-Pierre 2005;Kussamaul2005;Sommers, 2003).

\section{The Prominent Figures in Translation and Their Heyday}

With abrilliantidea,Venuti(2000)grouped the translation theoristsandtheir approachesbased on itsheyday and influence. Between 1900sand 1930swas the heydayof WalterBenjamin(19230, EzraPound(1929), JorgeLuisBorges(1935), JoseOrtegayGasset(1937). The period1940to1950 wasVladimir Nabokov(1955), JeanpaulVinayandJeanDarbelnet(1958), WillardVOQuine(1959), Roman Jakobson(1958). The period1960sto1970swasEugineNida(1964), JCCatford(1965), JiriLevy(1967), KatharinaReiss(1971), JamesS.Holmes(1972), GeorgeSeiner(1975), ItamarEven-Johar(1978 / revised1990), GideonToury(1978/revised1995).

The 1980swasthe heyday of thetheoriesandapproachespresented byseveralexperts. Thisdecadebeganwithemergence ofbroad publicitybook entitledTranslation Studies(Bassnett, 1980)whichconsolidatedthe variousstrandsof researchtranslation, especiallyinEnglishnative speaking countries. This was followedbyHansJ.Vermer(1989), AndreLefevere(1982), WilliamFrawley(1984), PhilipE. Lewis(1985), AntoineBerman(1985), ShoshanaBlum-Kulka(1986), andLoriChamberlain(1988).

The 1990s emergedtheconceptualparadigmof translationstudyin the form ofa merger oftheoryandmethodologythat was different fromthe previousdecade, continuingsymptomsindisciplinessuch aspolysystem, skopos, poststructuralism, andfeminism. Moreover, that wasthe decade ofreflection on development oflinguistic, particularlypragmatics, critical discourse analysis, computerizedcorpora, and others.The influentialexpertinthisdecadeincludeAnnieBrisset(1990/1996), Ernst-August Gutt(1991), GayariChakravortySpivak(1992), KwameAnthonyAppiah(1993), BasilHatimandIanMason(1997), KeithHarvey(1998), andLawrenceVenuti(2000).

III. Theories and Approaches in Translation

3.1 Linguistic Meaning of Equivalence Approach The theoryandapproach to the natureof $\begin{array}{lll}\text { linguisticmeaningandequivalentsdevelopedbyJakobson(1959/2000: } & \text { 114). This }\end{array}$ approachclassifiestranslationintothreetypes: 
(1) intralingual translation, or rewording:aninterpretation ofverbalsignsby usingother signsin the same language.

(2) interlingual translation,or actualtranslation:aninterpretation ofverbalsignsby usingotherlanguages.

(3) intersemiotic translationortransmutation:aninterpretation ofverbalsignsby usingnonverbalsignsystems.

The use of interlingualtranslationi.e. whensomeonewants to saysomethingin another wayin the form ofaphraseortextin the lame huagetoexplainorclarifysomethingthat beendescribedorwritten.Intersemiotictranslationis conveyed forwrittentext intomusic, moviesorpaintings. Theinterlingualtranslationis traditionaltranslationthat has been the objectofmany translation studies. Furthermore, there are twomain goalsof thistranslationstudies:

(1) Todescribethe phenomenon oftranslationandtranslation productasexperienced in real world

(2) Toestablishgeneral principlesby usingthe phenomena thatexplainableandpredictable.

Jakobsonproposedthat allcognitiveexperienceandits classificationcan be delivered withinthe existinglanguage.' (1959:238). The key issueinitiatedwas concerning the linguistic meaningandequivalents. This approach followedthe Saussure's ideasof the arbitrariness of the signifier(oral and written sign) andthe signified(the sign concept). Signifierandsignifiedform alinguisticsign, butthe signwasarbitraryandwas notmotivated(Saussure 1916/1983: 67-69). For example, theword'cheese'isacousticsignifierthat showsthe concept offood, madeofcompactedstarchmilk(signified).

Interlingualtranslationthat involves

replacingthe

naturalmessage

inonelanguagenotforseparatecodeunitsbutforentiremessagesinotherlanguages. The translatorrecodifyandtransfer messagesreceivedfromother sources. Therefore, the translationinvolves twoequivalentmessagesintwodifferent codes(Jakobson1959/2000: 114).

Forany messagesthat matchtheSTandTT, the units ofthe codewillbe differentforthese codesin twodifferent signsystems(different languages). From the point oflinguisticsandsemiotics, Jakobsondiscussesthe issue ofdefinition and equivalence, that isthe equivalent ofthedifferenceas an importantlinguisticconsiderations today. The problemof meaningandequivalentsfocusesondifferencesin the structure ofthe languageandterminologyrather than theinability oflanguagetobringthe messagethathad beenwrittenin other verbal languages.

\subsection{The Equivalence Theory}

The equivalence theories andapproachesin translationwas initiatedbyEugeneNida. This theoryevolvedfromhisexperiencefromthe 1940sonwardswhenhe translatedandorganized thetranslation of the Bible. This theoryusedin both of his works:(1) Toward aScience ofTranslating(1960), and(2) Theory and Practice of Translation(NidaandTaber, 1969). Nida'sapproachmoresystematicallyafteradoptingthe theoretical andterminologysemanticsandpragmatics concepts, andChomsky'stransformational-generative grammar.

Nidaclassifymeaning intotwo classes, (1) the linguisticmeaning(borrowing the elements ofChomsky'smodel), (2) referentialmeaning(denotative). A series oftechniquesadaptedfromvarious worksin linguisticsstudy andservedasguidance for translator inseeking thereferentialandemotivemeaning(connotative),focusesonthe analysis ofwordstructureanddistinguishesthe samewordsin related lexicalfield. In general, the component analysistechnique is intendedas the way toexplain theambiguity, avoidingthe fuzzy parts, andidentify thecultural differences.

Regarding the equivalence, Nidaproposedtwotypes of equivalence:(1) the formalequivalent, and(2) the dynamicequivalent(1964a: 159). The formalequivalent focus onthe message itself, bothform and content..., thatthe messagein TLshould matchedas little as possiblethe differentelementsin theSL. The formal equivalence carefullyoriented to theformalstructure ofthe SL, whichusesa stronginfluencein determiningthe accuracyandcorrectness.

The dinamyc equivalent based on the principle of equivalent effect where the relationship between the recipient and the message substantially same as the original one. Messages should be created for the recipient and linguistic needs and cultural expectations'leads to fairness of complete expression'. The purpose of dynamic equivalents is looking for the closest natural equivalent of SL message.

On another occasion, Nida describedthat the translation activities requires sophisticated knowledge of source and target languages. Translation is viewed as the process of communicating the foreign text based on the universality equivalence of cultural language. Translation involves double action, that communicate and represent not merely one language, but also two different languages. The first process is analyzing the text of SL, that can be examined from various aspects. They are includes (a) analyzing the grammatical relationship between the constituent parts, (b) identify the meanings of semantic units. The nonlinguistic analysis employed to get the message in the text, socio-cultural background of the speaker, elements that are closely related to the communication situation where the text was used, and condition of users. The next phase isparsingthe text into units of basic structure and semantics. The goal is to assure that there are no more points are lost. 
The chartbelowillustrates theprocess of conveyingthe messagethat consistofthe basicunits translation, thenreconstruct therawtranslationresultsintosemanticunitsin accordancewith the wishes oftheusers. (Nida in Dil(ed). 1975:80).

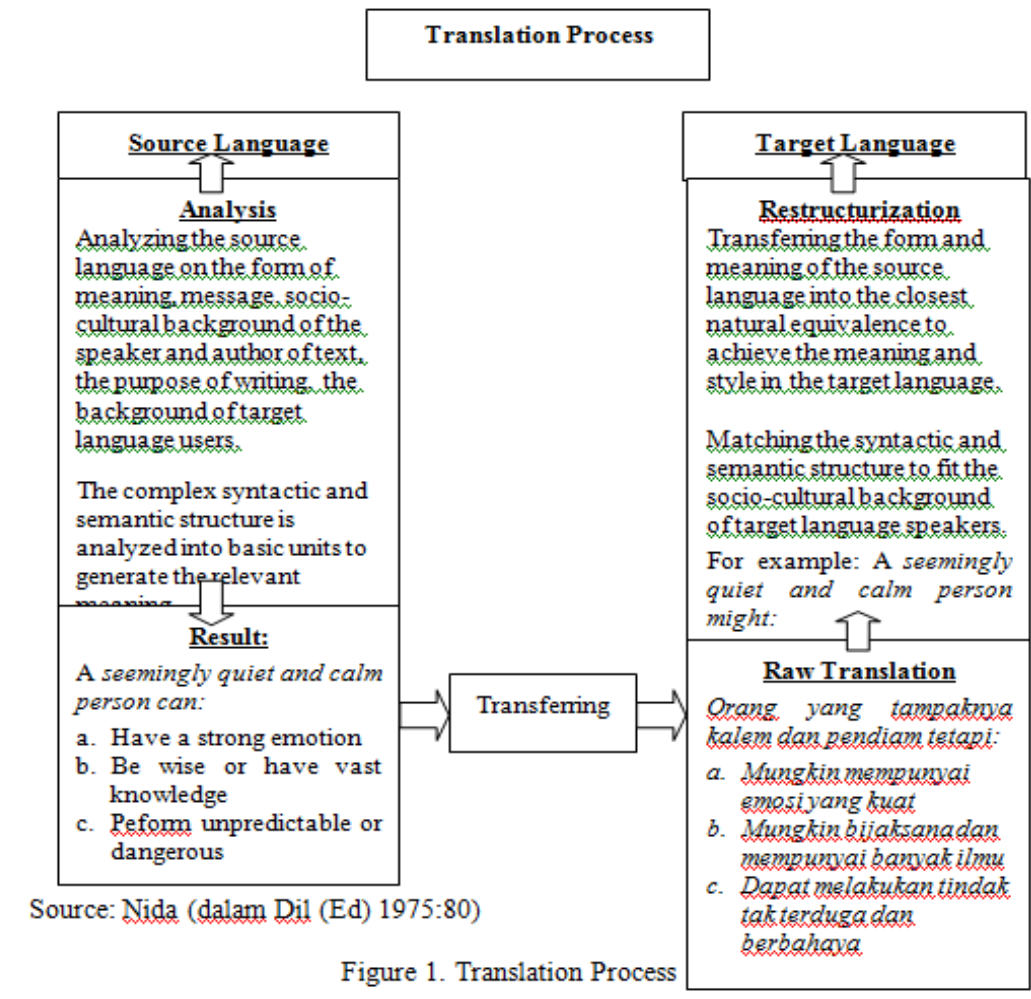

\subsection{SemanticsandPragmaticsTheory}

Semanticandpragmatictheorywas

proposedbyPeterNewmark.

This

theoryis classifiedonSemanticandCommunicative Translation. The two ofhis great workare(1) Approaches toTranslation (1981), and(2) ATextbookof Translation(1988).

The Newmark'sapproachdeparts fromthe ideaofNida. In avoiding the common term, especially onSLandTL, Newmarkusedthe term'semantic translation' and'communicative translation'. The semanticone translate thesyntacticandsemanticstructureof TL andcontextualmeaningas close aspossibleto SL. And the communicativetranslationtriestogenerateaneffectfor thereadersto gainauthenticity. (Newmark1981:34).

The description ofcommunicativetranslationis similar todynamicequivalentsuggestedby Nida, while the semanticone is equal toformal equivalent.

\subsection{The Functional Approach}

Reissdeveloped the concept ofequivalencethat focusedontext, rather than wordorphrase, the degree to whichcommunicationsmay be obtainedandthe equivalentmust be obtained(Reiss 1977/89: 1,130,114). The functionalapproachaimedtosystematicassessment of translation. His approach based oncategorization oflanguagefunctionsinitiatedbyKarlBuhler. Reissconnectedthese functionstodimensions oflanguageandtype of textorsituation of communication used. The characteristics ofthe type oftextcan be viewed asfollows:

1) Communicationabout thesimplefacts: information, knowledge, opinions, and others. The dimensions ofthe languageto conveythe informationislogic, referential, the main focus of communication is contentortopics, andthe type oftextisinformative.

2) Creativecomposition: the authorusesthe aestheticdimension oflanguage. The authororsenderset onforeground, as well asthe form ofthe message, andthe texttypeisexpressive.

3) The response stimulationof behavior: The objectivefunctionistoemergeorconvince the readeror recipient of textto actin acertain way. Languageis aform ofdialogue, focusoroperativeappointment.

4) Audiomedial text, such asfilmsorcommercialssoundorvisualsthataddthreeother functionswithvisual images, music, and others.

Reiss(1971: 54-88) alsolisteda setof criteriaof intralinguisticand extralinguisticinstructions where thecompleteness ofTTcan beassessed.

1) Intralinguistic criteria: semantic, lexical, grammatical, andstylistic characteristics. 
2) Extralinguistic criteria: situation, subject, field, time, place, recipient, sender, and implications ofsuchaffectivehumor, emotion, andridicule.

Despite the relatedness, the interests of the above criteria isvary, according to the type of text. For example, any translation of text content-focused, in the first place should lead to the retention of semantic equivalent. However, the TTof news article put grammatical criteria in the second place; the popular science books will be more attention on individual styles of the ST. Similarly, itsmore important to retain metaphor in expressive text translation rather than informative TL, where the semantic value of the translation itself will suffice.

\subsection{Skopos Theory}

This theoryproposed byHansVermeer. Skoposin Greekmeans'purpose' andhas beenintroducedin the1970sbyHansVermeeras atechnical termforthe purpose ofatranslationandtranslational action. The mainwork ofskopos(Skopostheorie) wasGrundlegungeinerallgemeineTranslationstheorie(Groundwork for aGeneral Theory ofTranslation). Despite skopospredatedthe translational action theorythat initiatedbyHolz-Manttari, this theoryis considered to bepart ofthe same theory. The Skoposfocusesonthe purpose ofthetranslationthat determinesthe methodsandstrategiesundertakentoproducethe translation resultsthat are functionallyappropriate. For Vermeer, these resultscalledtranslatum. Hence, the skoposfigure outwhyaSL translated andhow the TL functionswillbeimportant for thetranslator.

ReissandVermeer(1984:119) suggests ageneraltheoryfor thetranslation ofthe whole text. There are sixbasicprinciplesofthis theory:

1) Translatum(TT) is determinedbyits skopos

2) TTisanofferof informationinthe targetcultureandTLconcerningtheofferingof informationinthe sourcecultureandSL.

3) TTdoes notinitiateanofferof informationin a waythat clearlycouldbe reversed.

4) TTmust beinternallycoherent/related

5) TTmust becoherentwithTS.

\subsection{Systemic Functional Linguistics Theory}

Systemicfunctionaltheoryof translationformulated byM.A.KHalliday, thenknown as theHalliday Model. The text analysisbasedonthe SystemicFunctionalGrammar, that capable ofassessingthe languageascommunication, assumed themeaning inlinguisticoptionsandthe readersystematicallyconnectthese choicesina framework ofa widersocio-cultural.

There is astrongrelationbetweenthe realization oflinguisticsatthe surfacelevelandthe socioculturalframework. Hallidayoutlinedthe relationshipof genresandregisterswiththe language. Genre(the text typesareconventionallyassociatedwithspecificcommunicationfunctions, such as business letters), conditioned byenvironmental/socio-culturalsituationanddetermine theother elementswithina systemicframework.

The registerconsists of threevariableelements:

1) Field: about what iswritten, for examplespeech;

2) Tenor: who iscommunicatingandto whom, for example,the field ofmarketingto consumers;

3) Model: forms of communication, such as writing

Theseregistersvariablesassociatedwithstrandsof meaning. Thesestrandstogetherformsthe semanticdiscourseof anytextthat containedthree metafunction: ideational, interpersonal, andtextual. The metafunction is formedorrealized bylexicogrammar, i.e.choicesof words andsyntacticstructures.

The textfieldassociatedwiththeideationalmeaningthat is realizedthroughtransitivitypatterns(types of verbs, the structure ofthe active/passive, participantsintheprocess, etc.). Tenoris atextassociatedwithinterpersonalmeaningthat realizedthroughthe patterns ofmodality(capital verbsand adverbs, such ashopefully, should, possibly, andevaluativelexis, suchasbeautiful, dreadful, etc.). The modeof text associatedwiththe structured meaning thatrealizedthroughthe thematicstructureandinformation(especially the orderand arrangementof the elements inaclauseandcohesion(themannerof text lexically interdependent, includingthe use ofpronouns, ellipsis, wordcollocation, repetition, etc.)

The analysis of metafunctionhasa majorplacein this model. The closeness ofthe relationshipbetween the lexicogrammarpatternsandmetafunctionimplies thatthe analysis oftransitivity patterns, modality, thematicstructureandcohesionin the textrevealed howmetafunctionworksandhowthetextis meaningful(Eggins2004:210-2013). 
The

Indonesian

\section{Conclusion}

proverb 'takkenalmakataksayang'appliesinthis

paper.

Withoutrecognizingcharactersandthe theory developedin any field, especiallyintranslation, it isdifficulttohandle the translationpractices. Hence, the light of their theoriesand approaches has broaden our perspective in practice. There are two importantwaysto be followed:the first iscomparingthe theoriesandapproaches, and the secondiscombiningthe relevant theoriesandapproach.

\section{References}

[1] Baker, M. (ed) (1997)The Rougledge Encyclopedia of Translation Studies, London: Routledge.

[2] Baker, Mona (1992) In Other Words: A Coursebook on Translation, London and New York: Routledge.

[3] Bassnett, S. and Lefevere, A (1990) Translation, History and Culture, London and New York: Pinter.

[4] Bassnett, S. (1991)Translation Studies, London: Routledge.

[5] Catford, J. C. (1965)A Linguistic Theory of Translation, London: Oxford University Press.

[6] --------(2000)Translation Shift in Translation Studies Reader, ed. By Lawrence Venuti, pp. London and New York: Routledge.

[7] Dil, Answar S. (ed) (1975)Language Structure and Translation, Essays by Eugene A. Nida, Stanford: Stanford University Press.

[8] Dryden, J. (1993)Metaphrase, paraphrase and immitation in R. Schulte and J. Beguenet (eds). (1992), pp. 17-31

[9] Eggins, S. (2004). An introduction to Systemic Functional Linguistics. London: Continuum.

[10] Fawcett, P. (1997)Translation and Language: Lignuistic Approaches Explained. Manchester: St. Jerome.

[11] Hatim, B. and I. Mason (1990)Discourse and the Translator. London: Longman

[12] -------(1997)The Translator as Communicator. London: Routledge.

[13] --------and Jeremy M. 1997. Translation: AN advanced resource Book. London: Routledge.

[14] Jakobson, R. (1959/2000). On linguistic aspects of translation, in L. Venuty (ed) (2000), pp. 113-18.

[15] Newmark, P. (1981)Approaches to Translation, Oxford and New York: Pergamon

[16] ------- (1988) A Textbook of Translation. Hertfordshire: Prentice Hall.

[17] Nida, E. (1964a)Toward a Science of Translating, Leiden: Brill.

[18] ---(2000)Principles of Correspondence, in L. Venuti (ed),pp. 126-140.

[19] ------- and C, Taber (1969)The Theory and Practice of Translation, Leiden: Brill.

[20] Nord, C.(1997)Text Analysis in Translation: Theory, Methodology, and Didactic Application of a Model for Translation-Oriented Text Analysis. Amsterdam: Rodopi.

[21] Shei, Cris C. C. (2005)Translation Commentary: A Happy Medium between Translation Curriculum and EAP [01-2005]. System, vo. 33.pp 309-25.

[22] Venuti, Lawrence (ed) (2000)Translation Studies Reader. London and New York: Routledge.

[23] ----- (ed) (1992). Rethinking Translation: Discourse, Subjectivity, Ideology,London: Routledge.

[24] ------(1995)The Translator's Invisibility: A History of Translation.

[25] Vermeer, H. J. (2004)Skopos and Commission in Translational ActioninTranslation Studies, ed. by Lawrence Venutipp 221232.London and New York: Routledge. 